\title{
Desenvolvimento, caracterização e análise sensorial de formulações alimentares com proteínas do soro de leite ou albumina para crianças
}

\author{
Development, characterization and sensory analysis of food preparations for children \\ containing whey proteins or albumin
}

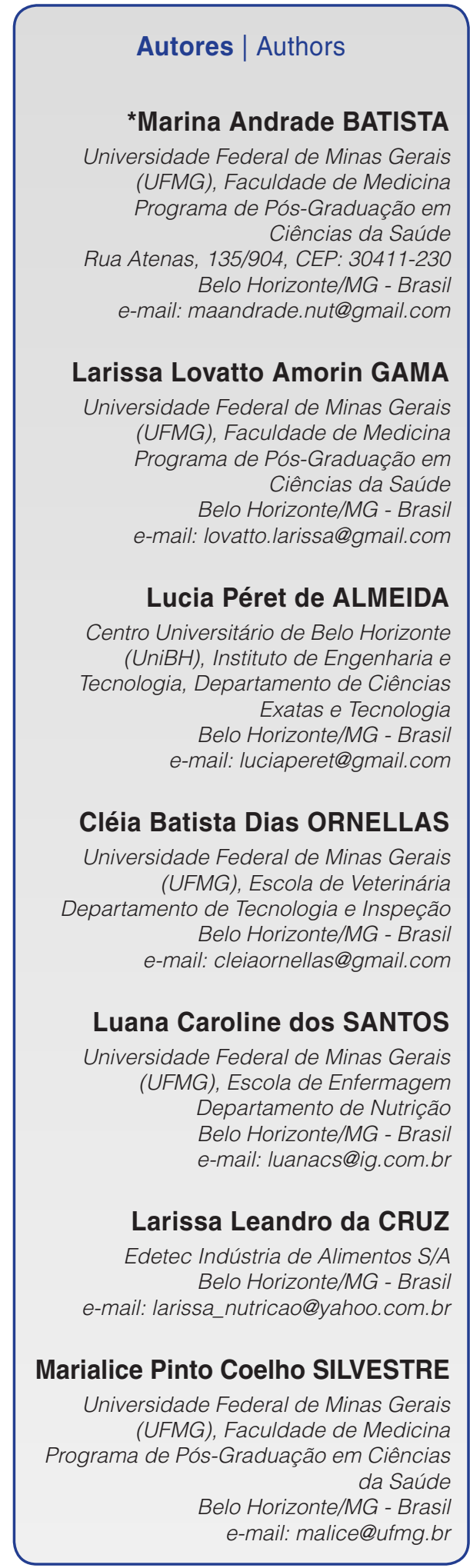

*Autor Correspondente / Corresponding Author

Recebido: Jun. 04, 2014

Aprovado: Abr. 06, 2015

\section{Resumo}

O presente trabalho visou verificar a elaboração, a caracterização e a avaliação da aceitação de duas formulações alimentares achocolatadas (uma contendo albumina e a outra, concentrado proteico de soro de leite - WPC) para crianças de 7 a 10 anos. O desenvolvimento das formulações baseou-se nas recomendações nutricionais para a faixa etária. Foram avaliados os seguintes parâmetros físico-químicos: composição química, estabilidade, pH, viscosidade e fluidez. A análise sensorial englobou as escalas hedônica de atitude, intenção de consumo e doçura e foi realizada por um grupo de 142 julgadores de um centro universitário, com média de 24,5 \pm 7,3 anos de idade e 66,2\% do sexo feminino. Todos os dados obtidos foram submetidos à análise estatística, adotando-se $\mathrm{p}<0,05$ como nível de significância. A composição química não diferiu em base seca ( $p>0,05)$. Observaram-se 3,88 (albumina) e 4,79 (WPC) vezes mais proteínas em $100 \mathrm{~mL}$ de amostra do que em bebidas comerciais. A primeira formulação mostrou-se mais viscosa (137,33 cP versus 22,33 cP da formulação com WPC) e menos fluida (percorreu $40 \mathrm{~mL}$ em 69 segundos versus 29 segundos da formulação com WPC). Quanto ao $\mathrm{pH}$, o produto com albumina apresentou característica alcalina $(8,60)$ e o com WPC ácida $(6,28)$. Ambas as formulações permaneceram estáveis e homogêneas após 24 horas de visualização. A análise sensorial mostrou que as formulações foram similares em todos os testes aplicados ( $p>0,05)$, sendo que as características mais bem avaliadas foram o sabor, a textura e a doçura, para ambas. Houve boa aceitação das formulações, com nota mediana de 7 e valores acima de $80 \%$ para a soma das respostas positivas nos testes. Conclui-se que as formulações alimentares analisadas apresentaram boas características físico-químicas e mostraram-se equilibradas nutricionalmente, com potencial para comercialização.

Palavras-chave: Análise sensorial; Crianças; Propriedades físicas; Propriedades químicas; Proteínas da clara do ovo; Proteínas do leite.

\section{Summary}

This work aimed to develop, characterize and evaluate the acceptance of two chocolate food preparations (one containing albumin and the other whey protein concentrate - WPC) for 7 to 10 year old children. The food preparations were created based on nutritional recommendations established for this age group. The following physicochemical parameters were evaluated: chemical composition, stability, pH, viscosity and fluidity. The sensory analysis included the hedonic and attitude scales, consumption intent and sweetness and was carried out by 142 judges from a university center, averaging $24.5 \pm 7.3$ years old, of which $66.2 \%$ were female. The data were submitted to a statistical analysis, adopting a significance level of $p<0.05$. The chemical compositions of the formulae did not differ on a dry weight basis ( $p>0.05$ ). Values of 3.88 (albumin) and 4.79 (WPC) times more protein were observed per $100 \mathrm{~mL}$ of sample than in a commercial beverage. The first preparation was more viscous (137.33 cP versus 22.33 in the WPC one) and less fluid (took 69 seconds for $40 \mathrm{~mL}$ to flow versus 29 by the WPC one). Concerning the $\mathrm{pH}$, the product with albumin was alkali (8.60) and that with WPC was acid (6.28). Both preparations were stable and homogeneous after $24 \mathrm{~h}$ visualization. The sensory analysis showed that the preparations were similar in 
BATISTA, M. A. et al.

\begin{abstract}
all the tests ( $p>0.05)$ and the best features for both were the flavour, texture and sweetness. Good acceptance of the preparations was observed, with a median score of 7 and values above $80 \%$ for the sum of the positive responses in the tests. In conclusion, the food preparations showed good physicochemical characteristics and were nutritionally balanced, with good market potential.
\end{abstract}

\title{
Key words: Sensory analysis; Children; Physical properties; Chemical properties; Egg white proteins; Dairy protein.
}

\section{Introdução}

As mudanças no comércio de gêneros alimentícios e a crescente exigência do consumidor - que busca alimentos cada vez mais saudáveis, com características sensoriais satisfatórias e capazes de prevenir doenças - incentivam a pesquisa de novos componentes naturais e ingredientes, bem como a inovação em produtos e a criação de nichos de mercado (LOPES et al., 2009; MOREIRA et al., 2010; SIQUEIRA et al., 2013).

Dentre esses componentes, destaca-se o soro de leite, subproduto da fabricação do queijo, que é composto por lactose (5\%), água (93\%), proteínas (0,9\%), vitaminas e minerais $(0,5 \%)$ e pequeno teor de gordura $(0,4 \%)$ (PESCUMA et al., 2010).

De todos os nutrientes do soro, as proteínas ganham evidência e apresentam alto valor biológico por serem ricas em aminoácidos essenciais de cadeia ramificada (leucina, isoleucina e valina) (PESCUMA et al., 2010). Além dos aspectos nutricionais, as proteínas do soro de leite possuem funções tecnológicas, que permitem sua ampla aplicação em alimentos e bebidas, melhorando propriedades como solubilidade, gelatinização, formação de espuma, tamponamento e emulsificação (JERVIS et al., 2012).

Essas proteínas são importantes, igualmente, pela sua ação biológica, por liberarem no organismo, durante o processo digestivo ou tratamento enzimático, peptídios bioativos, com diversos efeitos benéficos para a saúde (SOUSA et al., 2012; MORAIS et al., 2014; SILVA et al., 2014). Dentre as propriedades funcionais desses peptídios, pode-se citar as ações antihipertensiva (MORAIS et al., 2014; SILVA et al., 2014), hipocolesterolêmica, imunomoduladora (SINHA et al., 2007), antioxidante (SINHA et al., 2007; SILVESTRE et al., 2013), inibidora do apetite e redutora de gordura corporal (ZHOU et al., 2011; SOUSA et al., 2012).

Por se tratar de um resíduo poluente, grandes esforços se fazem necessários para transformar a grande quantidade de soro de leite gerada na indústria de laticínios em um produto adequado para consumo (PESCUMA et al., 2010). No Brasil, a produção de bebidas lácteas é uma das principais maneiras de aproveitamento do soro de leite fluido, porém observa-se que apenas 15\% do volume total é alocado para este fim (FERRARI et al.,
2013). Diante desse contexto, as alegações funcionais mencionadas, como controle do peso e redução do risco de desenvolvimento de doenças metabólicas e cardiovasculares, incitam ainda mais o emprego do soro de leite em produtos alimentícios e favorecem o seu reaproveitamento, com impacto positivo ao meio ambiente (SHI et al., 2011; GRAF et al., 2011).

Diversos ingredientes, derivados do soro de leite, também podem ser incorporados em alimentos e bebidas, contribuindo para sua reutilização, tais como o soro de leite em pó, com concentração de proteína de 11 a 14,5\%; o concentrado proteico de soro de leite (WPC - Whey Protein Concentrate), com teor proteico de 35 a 89\%; e a proteína isolada de soro de leite (WPI - Whey Protein Isolate), que contém, no mínimo, 90\% de proteína em sua composição (JERVIS et al., 2012).

Apesar da elaboração de produtos alimentícios enriquecidos com WPC já ter sido proposta em vários países e do seu comprovado papel na saúde, não existem no mercado brasileiro formulações para crianças que contenham exclusivamente este componente como fonte proteica. O consumo dessas formulações seria uma alternativa a ser introduzida na alimentação infantil como parte de hábitos de vida mais saudáveis.

Assim, o constante desafio das indústrias de laticínios e de pesquisadores consiste na criação de produtos que contenham WPC e sejam aceitos pelo consumidor. Para tal, a avaliação sensorial de novos produtos é essencial na identificação de variáveis que afetam o seu consumo (LOURES et al., 2010), e na detecção de suas características que são percebidas pelos órgãos da visão, olfato, paladar, tato e audição (ABNT, 1993).

Neste sentido, o presente trabalho teve como objetivos desenvolver, caracterizar e avaliar a aceitação de duas formulações alimentares (uma à base de WPC - pela sua funcionalidade e a outra de albumina - pelo seu baixo custo) destinadas a crianças.

\section{Material e métodos}

\subsection{Material}

Os ingredientes empregados no preparo das formulações alimentares foram os seguintes: maltodextrina (Neonutri Suplementos Nutricionais LTDA.); açúcar 
refinado (União ${ }^{\circledR}$; albumina em pó (Salto's Alimentos LTDA.) ou concentrado proteico de soro de leite (WPC 80 - Alibra $\left.{ }^{\circledR}\right)$; óleo de soja $\left(\right.$ Liza $\left.^{\circledR}\right)$; lecitina de soja $\left(\right.$ Lecmax ${ }^{\circledR}$ ); cacau em pó (Harald Indústria e Comércio de Alimentos LTDA.); aroma de chocolate em pó com baunilha (Givaudan ${ }^{\circledR}$ ); mascarante em pó para soja, com aroma idêntico ao natural de leite (Duas Rodas Industrial - Jaraguá do Sul, Brasil) e mix de vitaminas e minerais (M. Cassab Comércio e Indústria LTDA. - São Paulo, Brasil).

Para a pesagem dos ingredientes utilizou-se uma balança semianalítica (Gehaka ${ }^{\circledR}$, modelo: BG 2000, São Paulo, SP), com capacidade máxima de $2,020 \mathrm{~kg}$ e sensibilidade de $0,01 \mathrm{~g}$. A reconstituição e a homogeneização dos produtos em pó em água foram realizadas com auxílio de um liquidificador industrial (Skymsen ${ }^{\circledR}$, Modelo: LI-1,5, Brusque, SC). Na execução das análises de viscosidade e do $\mathrm{pH}$ foram aplicados o viscosímetro (HAAKE Viscotester ${ }^{\circledR}$ VT 51, Karlsruhe, Alemanha) e o pHmetro (Tecnal ${ }^{\circledR}$-2, Piracicaba, SP, Brasil), respectivamente.

\subsection{Métodos}

\subsubsection{Desenvolvimento e preparo das formulações em escala laboratorial}

Duas formulações alimentares sabor chocolate foram elaboradas com base nos valores de ingestão diária recomendada (IDR), com a finalidade de compor uma pequena refeição (10-20\% da IDR) para crianças entre 7 e 10 anos (IOM, 2000, 2001, 2005, 2010). Uma porção de cada produto equivaleu a $150 \mathrm{kcal}$ (55\% de carboidrato, $25 \%$ de proteína e $20 \%$ de lipídeo), sendo que um deles apresentou o WPC como fonte proteica (Formulação 1), enquanto que no outro foi utilizada a albumina (Formulação 2). Às formulações foram acrescidos o açúcar refinado, a maltodextrina, o óleo de soja, a lecitina de soja, o mix de vitaminas ( $A$ e C) e minerais ( $\mathrm{Ca}, \mathrm{Mg}$, Fe e $\mathrm{Zn}$ ), o aroma de chocolate, o mascarante de soja e o cacau em pó.

O cálculo teórico das quantidades dos nutrientes foi realizado considerando-se o teor informado no rótulo dos ingredientes. A quantidade de nutriente fornecida por porção de $100 \mathrm{~mL}$ de cada formulação pronta $(37 \mathrm{~g}$ reconstituídos em água) é de 9,40 g de proteína, 20,60 g de carboidrato, 3,33 g de lipídeo, 93,86 $\mu \mathrm{g}$ de vitamina A, $3,50 \mathrm{mg}$ de vitamina $\mathrm{C}, 231,40 \mathrm{mg}$ de cálcio, 0,90 mg de ferro, 20,0 mg de magnésio e 0,70 mg de zinco.

O preparo das formulações alimentares foi realizado em várias etapas. A primeira correspondeu à pesagem dos ingredientes secos (açúcar refinado, cacau em pó, aroma de chocolate, mascarante de soja e mix de vitaminas e minerais). Em seguida, o açúcar refinado foi macerado em um gral pequeno por 10 minutos para diminuição da granulometria e posterior adição dos outros ingredientes. O WPC e a albumina foram, então, pesados e acrescentados aos demais ingredientes secos e misturados até completa homogeneização (Mistura I). Posteriormente, a mistura 1 foi tamisada em peneira de 42 mesh por 2 minutos para a adição da base reservada (preparado de maltodextrina, óleo de soja e lecitina de soja) e novamente homogeneizada (Mistura II). Uma porção de $37 \mathrm{~g}$ da mistura 2, que representou a formulação em pó, foi acrescida de água até a obtenção de um volume final de $100 \mathrm{~mL}$ e agitada em liquidificador industrial por 1 minuto. Finalmente, as formulações prontas foram acondicionadas em utensílio descartável, bem vedado e mantidas sob refrigeração a $10{ }^{\circ} \mathrm{C}$ para realização da análise sensorial no mesmo dia e demais determinações em até 7 dias.

O uso de aditivos e a manipulação dos produtos atenderam às premissas estabelecidas pela Agência Nacional de Vigilância Sanitária (ANVISA) (BRASIL, 1997a, b).

\subsubsection{Caracterização físico-química das formulações}

\subsubsection{Composição química}

Todas as análises da composição química foram realizadas em triplicata, segundo as metodologias descritas pela Association of Official Analytical Chemists (LATIMER JUNIOR, 2012). A umidade foi determinada pelo método de secagem em estufa a $105^{\circ} \mathrm{C}$ até peso constante; as cinzas ou minerais, por incineração, em mufla a $550{ }^{\circ} \mathrm{C}$; as proteínas foram determinadas pelo método de micro-Kjeldahl, com fator de conversão de nitrogênio para proteína de 6,38. Os lipídios foram determinados pelo método de Bligh e Dyer (1959). O carboidrato foi calculado por diferença e o valor calórico a partir dos dados de composição centesimal, sendo utilizados os fatores de conversão de $4 \mathrm{kcal} . \mathrm{g}^{-1}$ para carboidratos e proteínas e de $9 \mathrm{kcal} . \mathrm{g}^{-1}$ para lipídeos.

\subsubsection{Análises físico-químicas}

Para a obtenção dos valores da viscosidade, um volume de $10 \mathrm{~mL}$ de cada amostra foi submetido ao método rotacional, utilizando-se o viscosímetro e a metodologia adaptada de Costa et al. (2013). O spindle utilizado foi $o L_{2}$ para albumina e $L_{1}$ para o WPC, na velocidade de 100 rotações por minuto (rpm), com torque de 30 a $70 \%$. A leitura foi realizada à temperatura ambiente e expressa em centipoise (cP).

A fluidez foi mensurada pelo método de gotejamento gravitacional ( $\mathrm{mL} /$ minuto), adaptado de Ferreira (2009), à temperatura ambiente. Completou-se o volume de uma seringa de $60 \mathrm{~mL}$ com a amostra e mediu-se o tempo estimado para que o líquido atingisse a marca de $20 \mathrm{~mL}$.

A medida do $\mathrm{pH}$ foi conduzida introduzindo-se o eletrodo do pHmetro, previamente calibrado, diretamente 
em $10 \mathrm{~mL}$ de amostra homogênea (LATIMER JUNIOR, 2012), à temperatura ambiente.

Para a verificação da estabilidade e da homogeneidade, as formulações alimentares (100 mL) foram transferidas para provetas de $250 \mathrm{~mL}$, mantidas à temperatura de refrigeração $\left(10^{\circ} \mathrm{C}\right)$ e observadas por inspeção visual durante 24 horas (0, 3 e 24 horas) (LOPES et al., 2011). Nos três diferentes tempos, foi investigada a formação de espuma e/ou separação de fases em todas as amostras.

\subsubsection{Análise sensorial}

\subsubsection{Casuística}

Participaram da pesquisa 142 voluntários, potenciais consumidores de bebida achocolatada, não treinados, da comunidade acadêmica do Centro Universitário UNI-BH, envolvendo estudantes, professores e funcionários, com média de 24,5 $\pm 7,3$ anos de idade. Desses, $66,2 \%$ eram do sexo feminino e $74,6 \%$ possuíam ensino superior incompleto. O convite foi realizado por meio de cartazes de divulgação da análise sensorial na instituição de ensino. Todos os voluntários assinaram o Termo de Consentimento Livre e Esclarecido (TCLE) (BRASIL, 2013a) e responderam a um questionário sobre os hábitos de consumo de bebidas achocolatadas.

Cumpre destacar que os testes para a avaliação sensorial das formulações foram, inicialmente, realizados com provadores adultos a fim de definir detalhadamente os aspectos menos aceitos nos produtos e otimizar o processo de melhoria dos mesmos. Além disso, os adultos são os responsáveis pela compra dos produtos que serão consumidos pelas crianças, especialmente quando elas demandam uma atenção nutricional especial. Num segundo momento, será conduzida a análise sensorial com crianças, público-alvo dos produtos testados.

O projeto foi aprovado pelo Comitê de Ética em Pesquisa da Universidade Federal de Minas Gerais (UFMG), sob número de registro CAAE - 0592.0.203.00011.

\subsubsection{Testes de aceitação}

\subsection{Escala hedônica}

Avaliou-se a aceitação global das duas formulações achocolatadas com diferentes fontes proteicas (albumina ou WPC), utilizando-se o método sensorial afetivo, por meio de escala hedônica de 9 pontos, em que o ponto 1 correspondia a "desgostei extremamente" e o ponto 9 a "gostei extremamente". A escala hedônica para o grau de doçura, de 5 pontos, também foi aplicada, sendo que o valor 1 significou "muito menos doce que o ideal" e o valor 5 "muito mais doce que o ideal" (DUTCOSKY, 2013; MINIM, 2013).

\subsection{Escala de Atitude (FACT)}

No mesmo formulário de avaliação, entregue ao julgador, foram incluídas duas escalas de cinco pontos: atitude (1 e 5 representaram, respectivamente, "não compraria" e "certamente compraria") e de intenção de consumo estruturada (1: "nunca consumiria" a 5: "consumiria sempre que tivesse oportunidade") (DUTCOSKY, 2013; MINIM, 2013).

As formulações foram preparadas no Laboratório de Técnica Dietética e os testes aplicados no Laboratório de Análise Sensorial, ambos do Centro Universitário UNI-BH. Este último era equipado com cabines individuais, onde se empregou luz branca. As amostras foram codificadas com algarismos de três dígitos e apresentadas de forma monádica, sequencial, utilizando-se um delineamento de blocos completos balanceados, servidas a $10^{\circ} \mathrm{C}$, em um volume de $30 \mathrm{~mL}$. Antes da oferta de cada amostra, foi oferecido um copo contendo água para eliminar interferências no sabor dos produtos.

Os voluntários foram questionados, ainda, sobre o que mais gostaram e o que menos gostaram das formulações, e se aumentariam o consumo caso estivem associadas a benefícios à saúde.

\subsubsection{Análise estatística}

Inicialmente todos os dados foram submetidos ao teste Shapiro-Wilk para avaliar a adesão das variáveis à distribuição normal. A análise descritiva foi realizada, seguida da estatística inferencial dos resultados por meio do Teste t de Student para comparação de médias, e pelo Teste Qui-Quadrado para comparação das proporções. Os resultados da análise sensorial foram analisados por meio de estatística descritiva, a partir das medidas de tendência central e dispersão, e da aplicação do Teste Mann-Whitney para a comparação das medianas. Utilizou-se o programa estatístico IBM SPSS Statistics ${ }^{\circledR}$ (Statistical Package for Social Sciences), versão 19 (Chicago, Illinois, EUA), adotando-se 5\% como nível de significância $(p<0,05)$.

\section{Resultados e discussão}

Os teores dos constituintes das formulações estão apresentados na Tabela 1. Foram identificadas diferenças em termos de base úmida, que devem estar associadas ao fato de que, para o ajuste do volume final para $100 \mathrm{~mL}$ foi necessário adicionar um volume maior de água (90 mL) para a formulação com albumina do que a com WPC (70 mL). Esse ajuste divergiu, provavelmente, diante das particularidades da composição química dos dois ingredientes comerciais (albumina e WPC) e refletiu, portanto, em menores teores de carboidratos, proteínas e lipídeos e, consequentemente, o valor energético total 
Desenvolvimento, caracterização e análise sensorial de formulações alimentares com proteínas do soro de leite ou albumina para crianças

BATISTA, M. A. et al.

foi inferior na formulação com albumina em relação à que contém WPC.

Contudo, essas diferenças desaparecem quando se elimina o teor de umidade para obter a composição química em base seca, uma vez que não foram observadas diferenças significativas para esses nutrientes entre as duas formulações.

Para a discussão dos dados das formulações, optou-se pela comparação com três marcas existentes no mercado, a partir da média dos componentes informados nos rótulos dos produtos. Essa comparação baseou-se no fato de que, como não existe classificação para as formulações desenvolvidas, segundo a legislação brasileira (BRASIL, 2005, 2010a), os produtos comerciais que mais se assemelham a elas são as bebidas lácteas achocolatadas não fermentadas.

Confrontando-se a composição química (em base úmida) das duas formulações (Tabela 1) com a média de dados obtida dos rótulos nutricionais de três bebidas achocolatadas comerciais, evidenciam-se maiores teores de proteínas e valor energético para as formulações aqui preparadas, visto que as informações nutricionais indicaram valores médios de $87,00 \mathrm{Kcal}, 15,00 \mathrm{~g}$ de carboidrato, 1,80 g de proteína, 2,20 g de lipídeo e 0,58 g de cinzas em uma porção de $100 \mathrm{~mL}$.

Quanto aos percentuais de macronutrientes das formulações, considerando a distribuição das calorias totais por $100 \mathrm{~mL}$, aquela com albumina apresentou $56,40 \%$ de carboidrato, 22,90\% de proteína e 20,70\% de lipídeo; a que continha WPC possuía $56,50 \%$ de carboidrato, $23,40 \%$ de proteína e 20,10\% de lipídeo; e as bebidas comerciais tinham, em média, $69,00 \%$ de carboidrato, 8,30\% de proteínas e 22,70\% de lipídeo. Assim, percebe-se que as formulações aqui desenvolvidas foram estatisticamente similares $(p>0,05)$ e equilibradas energeticamente, pois a faixa de distribuição calórica recomendada para escolares é de $45-65 \%$ de carboidrato, $10-30 \%$ de proteína e 25-35\% de lipídios (IOM, 2005). Ainda em relação à distribuição calórica, continham significativamente menos carboidratos, mais proteínas e menos lipídios do que as bebidas lácteas comerciais. As formulações elaboradas poderiam, igualmente, ser categorizadas como produtos alimentícios fontes de proteína, vitamina A e cálcio, por atenderem às preconizações da ANVISA para estes nutrientes (BRASIL, 2012).

Deve-se ressaltar outro aspecto, que a quantidade e a qualidade dos produtos divergem: as duas formulações poderão ser consumidas por crianças, em porções diárias de $100 \mathrm{~mL}$ e possuem o óleo de soja como fonte de lipídeos insaturados e a maltodextrina como fonte de carboidrato, além de conterem 3,88 (albumina) e 4,79 (WPC) vezes mais proteínas de alto valor biológico. Por outro lado, as bebidas lácteas são comercializadas em porções de 200 $\mathrm{mL}$ e, posto que exibam valor calórico próximo ao de uma porção das duas formulações, geralmente apresentam açúcares simples como principal fonte de carboidratos, bem como gorduras láctea e hidrogenada como fonte de lipídeos essencialmente saturados. O consumo frequente destes compostos pode favorecer o ganho de peso e doenças relacionadas (BORTOLI et al., 2011), ao passo que as formulações alimentares desenvolvidas no presente estudo representam alternativas mais saudáveis para inclusão na alimentação de crianças.

Os resultados dos aspectos físico-químicos das formulações analisados se encontram expostos na Tabela 2.

Ressalta-se que embora a viscosidade da formulação com albumina tenha sido, provavelmente em virtude da maior capacidade de absorção de água e de expansão desta proteína (LIMA et al., 2007), superior à daquela com WPC, as proteínas do soro de leite também agregam partículas e promovem a retenção hídrica (CRISTAS, 2012), além de manter a coesão em alimentos por meio da formação de géis (KUHN e SOARES, 2002; ALMEIDA, 2010; CRISTAS, 2012). Sendo assim, esses resultados podem ser positivos na aceitação dos produtos desenvolvidos, aumentando a satisfação dos consumidores (COSTA et al., 2013).

Tabela 1. Composição química das formulações alimentares.

\begin{tabular}{|c|c|c|c|c|}
\hline \multirow[b]{2}{*}{ Composição } & \multicolumn{2}{|c|}{ Base úmida $(\mathrm{g} / 100 \mathrm{~mL})$} & \multicolumn{2}{|c|}{ Base seca $(g / 100 \mathrm{~g})$} \\
\hline & $\begin{array}{c}\text { Formulação com } \\
\text { Albumina }\end{array}$ & $\begin{array}{c}\text { Formulação com } \\
\text { WPC* }^{*}\end{array}$ & $\begin{array}{c}\text { Formulação com } \\
\text { Albumina }\end{array}$ & $\begin{array}{c}\text { Formulação com } \\
\text { WPC* }\end{array}$ \\
\hline Valor energético (Kcal) & $121,80^{b} \pm 0,51$ & $147,46^{a} \pm 0,40$ & $443,02^{a} \pm 0,24$ & $444,02^{a} \pm 0,32$ \\
\hline Carboidratos & $17,17^{b} \pm 0,13$ & $20,81^{a} \pm 0,15$ & $62,46^{a} \pm 0,31$ & $62,66^{a} \pm 0,25$ \\
\hline Proteínas & $6,98^{b} \pm 0,05$ & $8,63^{a} \pm 0,09$ & $25,39^{a} \pm 0,17$ & $25,98^{a} \pm 0,10$ \\
\hline Lipídeos & $2,80^{b} \pm 0,06$ & $3,30^{\mathrm{a}} \pm 0,07$ & $10,18^{a} \pm 0,11$ & $9,94^{a} \pm 0,09$ \\
\hline Cinzas & $0,54^{\mathrm{a}} \pm 0,05$ & $0,47^{b} \pm 0,01$ & $1,96^{a} \pm 0,05$ & $1,41^{b} \pm 0,03$ \\
\hline Umidade & $72,51^{a} \pm 0,12$ & $66,79^{b} \pm 0,02$ & - & - \\
\hline
\end{tabular}

Dados expressos como a média de 3 repetições \pm desvio padrão. Médias indicadas por letras iguais não diferem entre si, a $5 \%$ de probabilidade, na mesma linha para a base seca e para a base úmida, separadamente. Dados em base seca não comparados com os de base úmida. *WPC = concentrado proteico de soro de leite. 
Tabela 2. Parâmetros físico-químicos das formulações alimentares.

\begin{tabular}{lrr}
\multicolumn{1}{c}{ Parâmetro } & \multicolumn{2}{c}{ Formulações } \\
& \multicolumn{1}{c}{ Albumina } & \multicolumn{1}{c}{ WPC* } \\
\hline Viscosidade (cP) & $137,33^{\mathrm{a}} \pm 0,58$ & $22,33^{\mathrm{b}} \pm 0,58$ \\
Fluidez (mL/minuto) & $34,78^{\mathrm{b}} \pm 0,12$ & $82,76^{\mathrm{a}} \pm 0,23$ \\
$\mathrm{pH}$ & $8,60^{\mathrm{a}} \pm 0,02$ & $6,28^{\mathrm{b}} \pm 0,03$ \\
\hline
\end{tabular}

Dados expressos como a média de 3 medidas \pm desvio padrão. Médias indicadas por letras iguais não diferem entre si a $5 \%$ de probabilidade na mesma linha. *WPC = concentrado proteico de soro de leite.

No que diz respeito à fluidez, pode-se verificar, a partir da Tabela 2, que a amostra contendo WPC mostrou ser mais fluida do que a que continha albumina, como esperado pelos resultados da viscosidade. Tais achados se devem às diferentes propriedades funcionais dessas proteínas e ao singular modo de interação com os demais componentes da formulação (COSTA et al., 2013), e justificam a diferença na quantidade de água necessária para reconstituição de cada formulação.

Não foram encontrados na literatura estudos que avaliaram a fluidez em bebidas lácteas comerciais. Entretanto, o mesmo método gravitacional, utilizado na corrente pesquisa, foi empregado por alguns autores para avaliar a fluidez de fórmulas enterais artesanais (HENRIQUES e ROSADO, 1999; ARAÚJO e MENEZES, 2006; MENEGASSI et al., 2007; VON ATZINGEN e SILVA, 2007; FERREIRA, 2009). Estas fórmulas são, geralmente, muito líquidas e algumas podem ser oferecidas oralmente. Desse modo, os trabalhos com elas realizados permitem a interface com os resultados encontrados para as formulações alimentares.

De acordo com Tagliari (2011), a viscosidade e, portanto, a fluidez de um produto alimentício ou solução podem variar conforme o tipo de proteína presente. Além disso, conforme Ferreira (2009), a fluidez de formulações enterais artesanais se diversifica muito dependendo dos alimentos utilizados. Entretanto, Ferreira (2009), estudando líquidos considerados brancos (água e leite), relatou que tanto a água como o leite demoraram 20 segundos para correr $40 \mathrm{~mL}$ pela seringa, o que demonstra que estes dois líquidos são mais fluidos e, consequentemente, menos viscosos que as formulações alimentares preparadas no presente estudo. Essas diferenças poderiam ser, pelo menos em parte, explicadas pelo fato dessas formulações apresentarem quantidades de proteínas superiores aos dos fluidos analisados por Ferreira (2009), uma vez que Tagliari (2011) afirmou que o aumento do teor proteico contribui para elevar a viscosidade de bebidas lácteas.

No tocante ao $\mathrm{pH}$, observou-se característica alcalina na formulação com albumina, em contraste com aquela com WPC (ligeiramente ácida/neutra). Destaca-se que bebidas lácteas não fermentadas possuem pH similar ao apresentado pela formulação contendo WPC, pois Lopes et al. (2011) obtiveram média de $\mathrm{pH}$ de 6,50 e Tagliari (2011) a média de 6,60 para esses produtos alimentares. Não foi encontrado na literatura qualquer estudo que demonstrasse o valor de $\mathrm{pH}$ de bebidas contendo albumina ou WPC.

Em relação à estabilidade, observou-se menor separação de fases e formação de espuma na formulação com albumina, principalmente nos tempos zero e após 3 horas de repouso. Após 24 horas de repouso, as duas formulações foram igualmente estáveis e homogêneas. A maior estabilidade da bebida contendo albumina em comparação com aquela com WPC, nos dois primeiros tempos, é devida à maior viscosidade apresentada pela albumina, originando uma formulação mais estável desde o início. A estabilidade final de ambas as formulações pode ter sido sustentada pela lecitina de soja, ingrediente que possui ação emulsificante e facilita a permeação das fases óleo-água. A comparação com outros dados da literatura não foi possível tendo em vista a inexistência de avaliações deste parâmetro com produtos semelhantes.

Em contrapartida, este procedimento vem sendo aplicado por alguns autores para avaliar a estabilidade de dietas enterais (ARAÚJO e MENEZES, 2006; MENEGASSI et al., 2007) e, mais recentemente, em estudo realizado pelo mesmo grupo de pesquisa do presente trabalho, de bebidas lácteas sabor chocolate adicionadas de ácido linoleico conjugado (CLA) (LOPES et al., 2011), com o intuito de se observar a separação de fases e a homogeneidade dos produtos finais. Nesses trabalhos, as soluções ficaram homogêneas, com aspecto uniforme e não foi observada a separação de fases das amostras após $24 \mathrm{~h}$ de repouso, o que também foi notado no presente estudo. Esses dados sugerem que as formulações alimentares se mantêm aptas para o consumo sob acondicionamento, sem alterações de suas características físico-químicas.

Quanto à análise sensorial, destaca-se, inicialmente, que do total de voluntários, $77,5 \%$ relataram que possuem o hábito de consumir bebidas achocolatadas e 90,2\% afirmaram que aumentariam o consumo dos produtos, caso soubessem que estes apresentassem propriedades funcionais que auxiliassem no controle das doenças associadas com o excesso peso. Esse resultado está de acordo com a afirmativa de que a tendência do consumidor é procurar produtos que melhorem a sua expectativa e qualidade de vida, informação que pode ser confirmada pelo aumento mundial do consumo de produtos funcionais (BRANDÃO, 2002; LOPES et al., 2009)

Dados da Pesquisa Nacional FIESP/IBOPE sobre o Perfil do Consumo de Alimentos, realizada em 2010 em várias capitais, mostraram que $34 \%$ dos consumidores brasileiros de alimentos priorizam a conveniência/ praticidade, 23\% a confiabilidade/qualidade, 22\% a 
Desenvolvimento, caracterização e análise sensorial de formulações alimentares com proteínas do soro de leite ou albumina para crianças

BATISTA, M. A. et al.

sensorialidade/prazer e $21 \%$ a saudabilidade/bem-estar e a sustentabilidade/ética. Um dos importantes resultados dessa pesquisa é a comprovação de que há hoje, no Brasil, uma forte adesão às quatro tendências atitudinais de consumo de alimentos, mencionadas anteriormente, já encontradas em outros países do mundo, sendo que a última possui forte potencial de crescimento na próxima década, em virtude da procura constante pela qualidade de vida (FIESP, 2010).

Considerando ainda as características dos produtos, 60\% alegam conhecer os alimentos funcionais e $70 \%$ dizem que leem o rótulo das embalagens (FIESP, 2010). Essas informações reforçam os resultados aqui obtidos.

Dentre as características sensoriais que os provadores mais gostaram nas formulações, as principais foram o sabor $(31,7 \%)$, a textura $(29,6 \%)$ e pouco açúcar $(16,9 \%)$, seguidas do aroma $(9,2 \%)$, cor $(4,9 \%)$ e aparência (1,4\%). Ainda, 3,5\% afirmaram que não aprovaram nada nos produtos e 2,8\% não responderam. Em contraste, os aspectos relacionados ao sabor (23,3\%) e à textura $(22,5 \%)$ foram também os mais apontados pela população analisada quando questionada sobre o que menos gostaram nas formulações. Além disso, $12,0 \%$ relataram que os produtos tinham pouco açúcar, $11,3 \%$ que possuíam pouco chocolate, 5,6\% disseram que continham muito açúcar, 4,9\% rejeitaram a aparência, 4,2\% a cor, 0,7\% o aroma, 3,5\% afirmaram que não reprovaram nada nos produtos e 12,0\% não responderam.

Os testes afetivos avaliam a resposta dos indivíduos com relação à preferência e/ou aceitação de um produto ou características específicas deste, utilizando consumidores habituais ou potenciais. Dessa maneira, a análise da aceitação reflete o grau em que os consumidores gostam ou desgostam de determinado produto (DUTCOSKY, 2013; MINIM, 2013).

Os valores apresentados na Tabela 3 revelam resultados idênticos das bebidas ofertadas, quanto à aceitação, frequência de consumo, certeza de compra e grau de doçura.

Verificou-se que houve boa aceitação das duas formulações achocolatadas, independentemente do seu alto teor proteico, uma vez que, na escala, o valor 7 corresponde a "gostei moderadamente" (Tabela 3). Segundo Ferrari et al. (2013), valores acima de 6 na escala hedônica indicam considerável aceitação e superior a 7 demonstram boa aceitação. Isso indica que as formulações se enquadram dentro dos padrões estabelecidos de aceitação.

De acordo com a escala hedônica, atribuíram nota 6 (gostei ligeiramente), 7 (gostei moderadamente), 8 (gostei muito) e 9 (gostei extremamente) ao produto com WPC, 23,9\%, 38,0\%, 16,9\% e 4,2\% dos provadores, respectivamente, perfazendo um total de $83,0 \%$ de respostas positivas. Já para a bebida contendo albumina, os percentuais foram de 22,5, 35,2, 22,5 e 9,9\%, correspondendo a um total de $90,1 \%$ de respostas positivas. As diretrizes do PNAE estabelecem que para que um novo produto seja inserido no seu cardápio, este deverá apresentar um nível de aceitação de 85\% junto aos beneficiários (BRASIL, 2010b, 2013b). Diante disso, os produtos elaborados poderiam ser incluídos, futuramente, nos processos licitatórios para a merenda escolar, como parte de uma alimentação saudável.

Ao avaliar a frequência de consumo, grande parte dos julgadores afirma que "consumiria se estivesse acessível, mas não me esforçaria para isto", enquanto que para a certeza de compra, "ocasionalmente compraria". Conforme a Pesquisa Nacional de Consumo de Alimentos, os fatores que os consumidores consideram na hora da compra são marca que confia/conhecida (59\%), ser gostoso/saboroso (47\%), ser mais nutritivo (32\%), ser um alimento de qualidade (29\%) e ser barato (28\%) (FIESP, 2010). Dessa forma, os resultados observados no presente trabalho podem estar vinculados ao fato de que as formulações ainda não são conhecidas e não estão disponíveis no mercado.

Quanto à doçura, a mediana da nota atribuída representa "levemente menos doce que o ideal", sendo um parâmetro considerado positivo pelos julgadores.

Não foram encontrados na literatura estudos que desenvolveram formulações achocolatadas contendo as proteínas utilizadas como fonte exclusiva deste macronutriente. Porém, existem trabalhos que formularam outras bebidas e preparações contendo soro de leite ou WPC. É importante ressaltar que as bebidas elaboradas não se enquadram na categoria de bebidas lácteas, pois o Regulamento Técnico de Identidade e Qualidade de Bebida Láctea (BRASIL, 2005) especifica que bebida láctea é o produto obtido a partir de leite ou

Tabela 3. Aceitação, frequência de consumo, certeza de compra e grau de doçura das amostras das duas formulações achocolatadas.

\begin{tabular}{ccccc} 
Amostra & Aceitação & $\begin{array}{c}\text { Frequência de } \\
\text { consumo }\end{array}$ & Certeza de compra & Grau de Doçura \\
\hline Albumina & $7^{a}(3-9)$ & $3^{a}(1-5)$ & $4^{a}(1-5)$ & $3^{a}(1-5)$ \\
WPC* & $7^{a}(1-9)$ & $3^{a}(1-5)$ & $4^{a}(1-5)$ & $3^{a}(1-5)$ \\
\hline
\end{tabular}

${ }^{*} \mathrm{WPC}=$ Formulação achocolatada contendo concentrado de soro de leite como fonte proteica. Valores expressos como mediana (valores mínimo e máximo). Letras sobrescritas iguais não diferem entre si estatisticamente ( $p>0,05)$, na mesma coluna. 
Desenvolvimento, caracterização e análise sensorial de formulações alimentares com proteínas do soro de leite ou albumina para crianças

BATISTA, M. A. et al.

leite reconstituído e/ou derivados de leite, fermentado ou não, com ou sem adição de outros ingredientes, no qual a base láctea representa pelo menos $51 \%(\mathrm{~m} / \mathrm{m})$ do total de ingredientes do produto. Contudo, as bebidas lácteas são os produtos que mais se assemelham às duas formulações desenvolvidas no presente estudo.

Vários trabalhos da literatura mostraram boa aceitação de preparações e produtos alimentícios contendo soro de leite. Assim, Ferrari et al. (2013), em uma pesquisa de análise sensorial com crianças, obtiveram nota média de 7 na bebida achocolatada, bolo e frapê de goiaba, todos contendo soro de leite como substituto total do leite. Um refrigerante adicionado de isolado proteico de soro de leite - WPI, concebido por Prado (2013), também demonstrou boa aceitabilidade, situando-se entre os termos hedônicos "gostei moderadamente" e "gostei muito", corroborando os resultados do presente estudo.

Estudo com bebidas achocolatadas contendo extrato solúvel de soja e soro de queijo mostrou, ainda, que a formulação elaborada somente com soro apresentou maior aceitação sensorial em relação aos atributos sabor e consistência (MOREIRA et al., 2010). Finalmente, foi relatado em pesquisa que todas as bebidas lácteas achocolatadas comerciais avaliadas tiveram boa aceitabilidade global, não apresentando diferença significativa entre si, assim como sua intenção de compra (PFLANZER et al., 2010).

Uma avaliação sensorial positiva foi similarmente relatada por alguns autores para outros alimentos contendo soro de leite. Zavareze et al. (2010) observaram que bolos adicionados de soro de leite in natura concentrado e desidratado apresentaram preferência por parte dos julgadores em relação ao bolo contendo o soro in natura e, como substituto de gordura, verificou-se que as características sensoriais do pão de queijo escaldado e do pão de queijo sem escaldamento estocados por até três meses não mostraram diferença significativa ( $p$ > $0,05)$, em relação a cada padrão, quando a gordura foi substituída em níveis de 50 e 100\% (ZAMBRANO et al., 2012). Com o propósito de exercer papel estabilizante/ espessante, bebidas fermentadas receberam, em sua composição, $1 \%$ de proteína e de concentrado proteico de soro, exibindo ausência de sinérese e viscosidade/consistência compatível com a de bebidas lácteas fermentadas comerciais, sendo aceitas pelos consumidores (Índice de Aceitabilidade - IA acima de $70 \%$ ) quanto aos atributos de aparência, aroma, sabor e textura (COSTA et al., 2013).

Percebe-se que, mesmo com outras aplicações, a incorporação de ingredientes à base de soro de leite e/ou proteínas do soro de leite é tecnologicamente possível, além de ser interessante também sob os pontos de vista ambiental e nutricional. Por exibir propriedades funcionais benéficas à saúde, o que representa uma grande vantagem em comparação com a albumina, o WPC permite a elaboração de produtos saudáveis e bem aceitos pelo consumidor em potencial.

\section{Conclusões}

As formulações alimentares apresentaram boas características físico-químicas, podendo, assim, contribuir para atingir de forma mais saudável as recomendações nutricionais de crianças de 7 a 10 anos. Do mesmo modo, estas formulações demonstraram ser equilibradas nutricionalmente, tanto em termos de distribuição calórica quanto de micronutrientes, contrastando com os demais produtos comerciais. As formulações exprimiram, ainda, boa aceitação geral, considerando os parâmetros avaliados, destacando-se as características sabor, textura e doçura.

\section{Agradecimentos}

À empresa Matrix Ingredientes (Belo Horizonte, Brasil), pela doação do aroma de chocolate em pó com baunilha (Givaudan ${ }^{\circledR}$ ). À empresa Duas Rodas Industrial (Jaraguá do Sul, Brasil), pela doação do mascarante em pó para soja e à M. Cassab Comércio e Indústria LTDA (São Paulo, Brasil), pela doação do mix de vitaminas e minerais. Ao Centro Universitário de Belo Horizonte (UNI-BH), pela disponibilização da Planta Piloto de Processamento e Tecnologia de Alimentos do Instituto de Engenharia e Tecnologia e dos Laboratórios de Análise Sensorial e de Técnica Dietética. À Edetec Indústria de Alimentos S/A (Belo Horizonte, MG, Brasil), pela disponibilização da infraestrutura e dos equipamentos de laboratório. Ao CNPq e à FAPEMIG, pelo apoio financeiro.

\section{Referências}

ALMEIDA, M. A. Transglutaminase e albumina de ovo em reestruturados cozidos congelados de frango. 2010. 92 f. Dissertação (Mestrado em Ciências)-Escola Superior de Agricultura "Luiz de Queiroz", Universidade de São Paulo, Piracicaba, 2010.

ARAÚJO, E. M.; MENEZES, H. C. Formulações com alimentos convencionais para nutrição enteral ou oral. Ciência e Tecnologia de Alimentos, Campinas, v. 26, n. 3, p. 1-6, 2006.

ASSOCIAÇÃO BRASILEIRA DE NORMAS TÉCNICAS - ABNT. NBR 12806: análise sensorial de alimentos e bebidas: terminologia. Rio de Janeiro, 1993.

BLIGH, E. G.; DYER, W. J. A rapid method of total lipid extraction and purification. Canadian Journal of Biochemistry and Physiology, Canada, v. 37, n. 8, p. 911-917, 1959. http://dx.doi. org/10.1139/059-099. PMid:13671378

BORTOLI, C.; BONATTO, S.; BRUSCATO, N. M.; SIVIERO, J. Ingestão dietética de gordura saturada e carboidratos em adultos e idosos com dislipidemias oriundos do Projeto 
Desenvolvimento, caracterização e análise sensorial de formulações alimentares com proteínas do soro de leite ou albumina para crianças

BATISTA, M. A. et al.

Veranópolis. Revista Brasileira de Cardiologia, Rio de Janeiro, v. 24, n. 1, p. 33-41, 2011.

BRANDÃO, S. C. C. Novas gerações de produtos lácteos funcionais. Revista Indústria de Laticínios, São Paulo, v. 6, n. 37, p. 64-66, 2002

BRASIL. Ministério da Saúde. Agência Nacional de Vigilância Sanitária. Portaria n 540 - SVS/MS, de 27 de outubro de 1997. Aprova o Regulamento Técnico: Aditivos Alimentares - definições, classificação e emprego. Diário Oficial [da] República Federativa do Brasil. Brasília, DF, 28 out. 1997a. Disponivel em: <http://portal.anvisa.gov.br/wps/wcm/connect/ d1b6da0047457b4d880fdc3fbc4c6735/PORTARIA_540_1997. pdf?MOD=AJPERES $>$. Acesso em: 13 fev. 2010.

BRASIL. Ministério da Saúde. Agência Nacional de Vigilância Sanitária. Portaria n 326, de 30 de julho de 1997. Dispõe sobre as Condições Higiênico-Sanitárias e de Boas Práticas de Fabricação para Estabelecimentos Produtores/Industrializadores de Alimentos. Diário Oficial [da] República Federativa do Brasil. Brasília, DF, 3 maio 1997b. Disponível em: <http://www. anvisa.gov.br/alimentos/legis/especifica/regutec.htm>. Acesso em: 13 Fev. 2010.

BRASIL. Ministério da Agricultura, Pecuária e Abastecimento. Instrução Normativa $n^{\circ} 16$, de 23 de agosto de 2005. Aprova o Regulamento Técnico de identidade e qualidade de bebida láctea. Diário Oficial [da] República Federativa do Brasil, Brasília, DF, 24 ago. 2005. Disponível em: <http://extranet. agricultura.gov.br/sislegis-consulta/consultarLegislacao.do?o peracao $=$ visualizar\&id=12792 $>$. Acesso em: 13 fev. 2010 .

BRASIL. Ministério da Saúde. Agência Nacional de Vigilância Sanitária. Resolução - RDC n 18, de 27 de abril de 2010. Dispõe sobre Alimentos para Atletas. Diário Oficial [da] República Federativa do Brasil. Brasília, DF, 28 abr. 2010a. Disponível em: <http://portal.anvisa.gov.br/wps/wcm/connect/52bee28047 45886b91ffd53fbc4c6735/RDC_18_2010.pdf?MOD=AJPERES>. Acesso em: 12 nov. 2013.

BRASIL. Ministério da Educação e Cultura. Fundo Nacional de Desenvolvimento da Educação. Manual para aplicação dos testes de aceitabilidade no Programa Nacional de Alimentação Escolar - PNAE. Brasília, DF, 2010b. Disponível em: <http:// www.fnde.gov.br/programas/alimentacao-escolar/alimentacaoescolar-material-de-divulgacao/alimentacao-manuais/ item/5166-manual-para-aplica\%C3\%A7\%C3\%A3o-dos-testesde-aceitabilidade-no-pnae>. Acesso em: 02 abr. 2014

BRASIL. Ministério da Saúde. Agência Nacional de Vigilância Sanitária. Resolução da Diretoria Colegiada - RDC n 54, de 12 de novembro de 2012. Dispõe sobre o Regulamento Técnico sobre Informação Nutricional Complementar. Diário Oficial [da] República Federativa do Brasil, Brasília, DF, 13 nov. 2012. Disponível em: <http://portal.anvisa.gov.br/ wps/wcm/connect/630a98804d7065b981f1e1c116238c3b/

Resolucao+RDC+n.+54_2012.pdf?MOD=AJPERES>. Acesso em: 12 nov. 2013
BRASIL. Ministério da Saúde. Conselho Nacional de Saúde. Resolução $n^{\circ}$ 466, de 12 de dezembro de 2012. Aprova as Diretrizes regulamentadoras de pesquisas envolvendo seres humanos. Diário Oficial [da] República Federativa do Brasil, Brasília, DF, 13 jun. 2013a. Disponível em: <http://conselho. saude.gov.br/ultimas_noticias/2013/06_jun_14_publicada_ resolucao.html>. Acesso em: 06 Mar. 2014.

BRASIL. Ministério da Educação e Cultura. Fundo Nacional de Desenvolvimento da Educação. Resolução/CD/FNDE n 26, de 17 de junho de 2013. Dispõe sobre o Atendimento da alimentação escolar aos alunos da educação básica no âmbito do Programa Nacional de Alimentação Escolar - PNAE. Diário Oficial [da] República Federativa do Brasil, Brasília, DF, 18 jun. 2013b. Disponível em: <http://www.fnde.gov.br/fnde/ legislacao/resolucoes/item/4620-resolu\%C3\%A7\%C3\%A3ocd-fnde-n\%C2\%BA-26,-de-17-de-junho-de-2013>. Acesso em: 12 nov. 2013.

COSTA, A. V. S.; NICOLAU, E. S.; TORRES, M. C. L.; FERNANDES, P. R.; ROSA, S. I. R.; NASCIMENTO, R. C. Desenvolvimento e caracterização físico-química, microbiológica e sensorial de bebida láctea fermentada elaborada com diferentes estabilizantes/espessantes. Semina: Ciências Agrárias, Londrina, v. 34, n. 1, p. 209-226, 2013.

CRISTAS, A. S. A. Capacidade de retenção de água e de gordura de diferentes concentrados proteicos usados em produtos cárneos emulsificados. 2012. 45 f. Dissertação (Mestrado em Engenharia Alimentar)-Instituto Superior de Agronomia, Universidade Técnica de Lisboa, Lisboa, 2012.

DUTCOSKY, S. D. Análise sensorial de alimentos. 4. ed. Curitiba: Champagnat, 2013. 531 p.

FEDERAÇÃO DAS INDÚSTRIAS DO ESTADO DE SÃO PAULO - FIESP. Brasil Food Trends 2020. São Paulo: FIESP/ITAL, 2010. Disponível em: <http://www.brasilfoodtrends.com.br/ Brasil_Food_Trends/index.html>. Acesso em: 02 abr. 2014.

FERRARI, A. S.; BALDONI, N. R.; AZEREDO, E. M. C. Análise sensorial e físico-química de produtos elaborados à base de soro de leite. Revista da Universidade Vale do Rio Verde, Três Corações, v. 10, n. 1, p. 216-223, 2013.

FERREIRA, R. S. Elaboração de fórmulas enterais artesanais de baixo custo adequadas em fluidez e osmolalidade. 2009. 89 f. Dissertação (Mestrado em Ciência da Nutrição)Universidade Federal de Viçosa, Viçosa, 2009.

GRAF, S.; EGERT, S.; HEER, M. Effects of whey protein supplements on metabolism: evidence from human intervention studies. Current Opinion in Clinical Nutrition and Metabolic Care, United States, v. 14, n. 6, p. 569-580, 2011. http://dx.doi. org/10.1097/MCO.0b013e32834b89da. PMid:21912246

HENRIQUES, G. S.; ROSADO, G. P. Formulação de dietas enterais artesanais e determinação da osmolalidade pelo método crioscópico. Revista de Nutrição, Campinas, v. 
Desenvolvimento, caracterização e análise sensorial de formulações alimentares com proteínas do soro de leite ou albumina para crianças

BATISTA, M. A. et al.

12, n. 3, p. 225-232, 1999. http://dx.doi.org/10.1590/S141552731999000300003 .

INSTITUTE OF MEDICINE - IOM; FOOD AND NUTRITION BOARD; STANDING COMMITTEE ON THE SCIENTIFIC EVALUATION OF DIETARY REFERENCE INTAKES. Dietary reference intakes for: vitamin $c$, vitamin e, selenium and carotenoids. Washington: The National Academy Press, 2000.

INSTITUTE OF MEDICINE - IOM; FOOD AND NUTRITION BOARD; STANDING COMMITTEE ON THE SCIENTIFIC EVALUATION OF DIETARY REFERENCE INTAKES. Dietary reference intakes for: vitamin a, vitamin $k$, arsenic, boron, cromium, copper, iodine, iron, manganese, molybdenium, nickel, silicon, vanadium and zinc. Washington: The National Academy Press, 2001. 797 p

INSTITUTE OF MEDICINE - IOM; FOOD AND NUTRITION BOARD; STANDING COMMITTEE ON THE SCIENTIFIC EVALUATION OF DIETARY REFERENCE INTAKES. Dietary reference intakes for: energy, carbohydrate, fiber, fat, fatty acids, cholesterol, protein, and amino acids (macronutrientes). Washington: The National Academy Press, 2005. 936 p.

INSTITUTE OF MEDICINE - IOM; FOOD AND NUTRITION BOARD; STANDING COMMITTEE ON THE SCIENTIFIC EVALUATION OF DIETARY REFERENCE INTAKES. Dietary reference intakes for: vitamin $\mathbf{d}$ and calcium. Washington: The National Academy Press, 2010.

JERVIS, S.; CAMPBELL, R.; WOJCIECHOWSKI, K. L.; FOEGEDING, E. A.; DRAKE, M. A.; BARBANO, D. M. Effect of bleaching whey on sensory and functional properties of $80 \%$ whey protein concentrate. Journal of Dairy Science, Champaign, v. 95, n. 6, p. 2848-2862, 2012. http://dx.doi. org/10.3168/jds.2011-4967. PMid:22612922

KUHN, C. R.; SOARES, G. J. D. Proteases e inibidores no processamento de surimi. Revista Brasileira de Agrociência, Pelotas, v. 8, n. 1, p. 5-11, 2002.

LATIMER JUNIOR, G. W. (Ed.). Official methods of analysis of the Association of Official Analytical Chemists. 19th ed. Arlington: AOAC International, 2012

LIMA, E. R. A.; TAVARES, F. W.; BISCAIA JUNIOR, E. C. Finite volume solution of the modified Poisson-Boltzmann equation for two colloidal particles. Physical Chemistry Chemical Physics, Cambridge, v. 9, n. 24, p. 3174-3180, 2007. http:// dx.doi.org/10.1039/b701170a. PMid:17612740

LOPES, D. C. F.; GERALDI, L. M.; AFONSO, W. D. O.; ORNELLAS, C. B. D.; SILVA, M. R.; CAMPOS, F. M.; GARCIA, E. S.; SILVESTRE, M. P. C. Development of a milk drink added of conjugated linoleic acid: use of a sensory evaluation. American Journal of Food Technology, New York, v. 4, n. 5, p. 210-217, 2009. http://dx.doi.org/10.3923/ajft.2009.210.217.

LOPES, D. C. F.; SILVESTRE, M. P. C.; CHIARINI-GARCIA, H.; GARCIA, E. S.; MORAIS, H. A.; SILVA, M. R. Evaluation of conjugated linoleic acid addition to a chocolate milk drink. International Journal of Food Engineering, Boston, v. 7, n. 2, p. 1-14, 2011. http://dx.doi.org/10.2202/1556-3758.1842.

LOURES, M. M. R.; MINIM, V. P. R.; CERESINO, E. B.; CARNEIRO, R. C.; MINIM, L. A. Análise descritiva por ordenação na caracterização sensorial de iogurte diet sabor morango enriquecido com concentrado protéico do soro. Semina: Ciências Agrárias, Londrina, v. 31, n. 3, p. 661-668, 2010.

MENEGASSI, B.; SANT'ANA, L. S.; COELHO, J. C.; MARTINS, O. A.; PINTO, J. P. A. N.; BRAGA COSTA, T. M.; NAVARRO, A. M. Características físico-químicas e qualidade nutricional de dietas enterais não-industrializadas. Alimentos e Nutrição, Araraquara, v. 18, n. 2, p. 127-132, 2007

MINIM, V. P. R. Análise sensorial: estudos com consumidores. 3. ed. Viçosa: Editora UFV, 2013. 332 p.

MORAIS, H. A.; SILVESTRE, M. P. C.; AMORIN, L. L.; SILVA, V. D. M.; SILVA, M. R.; SILVA, A. C. S.; SILVEIRA, J. N. Use of different proteases to obtain whey protein concentrate hydrolysates with inhibitory activity toward angiotensin-converting enzyme. Journal of Food Biochemistry, Westport, v. 38, n. 1, p. 102-109, 2014. http://dx.doi.org/10.1111/jfbc. 12032

MOREIRA, R. W. M.; MADRONA, G. S.; BRANCO, I. G.; BERGAMASCO, R.; PEREIRA, N. C. Avaliação sensorial e reológica de uma bebida achocolatada elaborada a partir de extrato hidrossolúvel de soja e soro de queijo. Acta Scientiarum Technology, Maringá, v. 32, n. 4, p. 435-438, 2010.

PESCUMA, M.; HÉBERT, E. M.; MOZZI, F.; VALDEZ, G. F. Functional fermented whey-based beverage using lactic acid bacteria. International Journal of Food Microbiology, Amsterdam, v. 141, n. 1-2, p. 73-81, 2010. http://dx.doi. org/10.1016/j.ijfoodmicro.2010.04.011. PMid:20483186

PFLANZER, S. B.; CRUZ, A. G.; HATANAKA, C. L.; MAMEDE, P. L.; CADENA, R.; FARIA, J. A. F.; SILVA, M. A. A. P. Perfil sensorial e aceitação de bebida láctea achocolatada. Ciência e Tecnologia de Alimentos, Campinas, v. 30, n. 2, p. 391-398, 2010.

PRADO, M. S. Elaboração de um refrigerante sabor laranja com adição de isolado proteico de soro de leite. 2013. 75 f. Dissertação (Mestrado em Tecnologia de Alimentos)Universidade Tecnológica Federal do Paraná, Londrina, 2013.

SHI, J.; TAURIAINEN, E.; MARTONEN, E.; FINCKENBERG, P.; AHLROOS-LEHMUS, A.; TUOMAINEN, A.; PILVI, T. K.; KORPELA, R.; MERVAALA, E. M. Whey protein isolate protects against dietinduced obesity and fatty liver formation. International Dairy Journal, Barking, v. 21, n. 8, p. 513-522, 2011. http://dx.doi. org/10.1016/j.idairyj.2011.03.006.

SILVA, M. R.; SILVESTRE, M. P. C.; SILVA, V. D. M.; SOUZA, M. W. S.; LOPES JUNIOR, C. O.; AFONSO, W. O.; LANA, F. C.; RODRIGUES, D. F. Production of ACE-inhibitory whey protein concentrate hydrolysates: use of pancreatin and papain. 
Desenvolvimento, caracterização e análise sensorial de formulações alimentares com proteínas do soro de leite ou albumina para crianças

BATISTA, M. A. et al.

International Journal of Food Properties, New York v. 17, n. 5, p. 1002-1012, 2014. http://dx.doi.org/10.1080/10942912.20 12.685821

SILVESTRE, M. P. C.; MORAIS, H. A.; SILVA, V. D. M.; SILVA, M. R. Whey as source of peptides with high antioxidant activity: use of a pancreatin and an Aspergillus sojae protease. Publicatio UEPG: Ciências Biológicas e da Saúde, Ponta Grossa, v. 19, n. 2, p. 143-147, 2013.

SINHA, R.; RADHA, C.; PRAKASH, J.; KAUL, P. Whey protein hydrolysate: functional properties, nutritional quality and utilization in beverage formulation. Food Chemistry, London, v. 101, n. 4, p. 1484-1491, 2007.

SIQUEIRA, A. M. O.; MACHADO, E. C. L.; STAMFORD, T. L. M. Bebidas lácteas com soro de queijo e frutas. Ciência Rural, Santa Maria, v. 43, n. 9, p. 1693-1700, 2013. http://dx.doi. org/10.1590/S0103-84782013000900025.

SOUSA, G. T.; LIRA, F. S.; ROSA, J. C.; OLIVEIRA, E. P.; OYAMA, L. M.; SANTOS, R. V.; PIMENTEL, G. D. Dietary whey protein lessens several risk factors for metabolic diseases: a review. Lipids in Health and Disease, London, v. 11, n. 67, p. 1-9, 2012. http://dx.doi.org/10.1186/1476-511X-11-67. PMid:22676328

TAGLIARI, M. Influência de diferentes hidrocoloides no comportamento reológico de bebidas lácteas não fermentadas. 2011. 75 f. Dissertação (Mestrado em Engenharia de Processos Químicos e Bioquímicos)-Centro Universitário do Instituto Mauá de Tecnologia, São Caetano do Sul, 2011.

VON ATZINGEN, M. C.; SILVA, M. E. M. P. Desenvolvimento e análise de custo de dietas enterais artesanais à base de hidrolisado proteico de carne. Revista Brasileira de Nutrição Clínica, São Paulo, v. 22, n. 3, p. 210-213, 2007.

ZAMBRANO, F.; SILVA, M. C.; ORMENESE, R. C. C.; YOTSUYANAGI, K. Concentrado proteico de soro como substituto de gordura em pão de queijo. Brazilian Journal of Food Technology, Campinas, v. 15, n. 3, p. 244-252, 2012. http://dx.doi.org/10.1590/S1981-67232012005000018.

ZAVAREZE, E. R.; MORAES, K. S.; SALAS-MELLADO, M. L. M. Qualidade tecnológica e sensorial de bolos elaborados com soro de leite. Ciência e Tecnologia de Alimentos, Campinas, v. 30, n. 1, p. 100-105, 2010.

ZHOU, J.; KEENAN, M. J.; LOSSO, J. N.; RAGGIO, A. M.; SHEN, L.; MCCUTCHEON, K. L.; TULLEY, R. T.; BLACKMAN, M. R.; MARTIN, R. J. Dietary whey protein decreases food intake and body fat in rats. Obesity : a Research Journal, Hoboken, v. 19, n. 8, p. 1568-1573, 2011. http://dx.doi.org/10.1038/oby.2011.14. PMid:21331067 


\section{Errata}

No artigo Desenvolvimento, caracterização e análise sensorial de formulações alimentares com proteínas do soro de leite ou albumina para crianças publicado no periódico Brazilian Journal of Food Technology, vol. 18, n. 1, p. 31-41, na página 39

Onde se lia:

"BRASIL. Ministério da Saúde. Agência Nacional de Vigilância Sanitária. Portaria n 540 - SVS/MS, de 27 de outubro de 1997. Aprova do Regulamento Técnico: Aditivos Alimentares - definições, classificação e emprego. Diário Oficial [da] República Federativa do Brasil. Brasília, DF, 28 out. 1997a. Disponível em: <http://portal.anvisa.gov.br/wps/wcm/connect/ d1b6da0047457b4d880fdc3fbc4c6735/PORTARIA_540_1997.pdf?MOD=AJPERES>. Acesso em: 13 fev. 2010."

Leia-se:

"BRASIL. Ministério da Saúde. Agência Nacional de Vigilância Sanitária. Portaria nº 540 - SVS/MS, de 27 de outubro de 1997. Aprova o Regulamento Técnico: Aditivos Alimentares - definições, classificação e emprego. Diário Oficial [da] República Federativa do Brasil. Brasília, DF, 28 out. 1997a. Disponível em: <http://portal.anvisa.gov.br/wps/wcm/connect/ d1b6da0047457b4d880fdc3fbc4c6735/PORTARIA_540_1997.pdf?MOD=AJPERES >. Acesso em: 13 fev. 2010."

\section{Onde se lia:}

"BRASIL. Ministério da Saúde. Agência Nacional de Vigilância Sanitária. Portaria n 326, de 30 de julho de 1997. Dispões sobre as Condições Higiênico-Sanitárias e de Boas Práticas de Fabricação para Estabelecimentos Produtores/ Industrializadores de Alimentos. Diário Oficial [da] República Federativa do Brasil. Brasília, DF, 3 maio 1997b. Disponível em: <http://www.anvisa.gov.br/alimentos/legis/especifica/regutec.htm>. Acesso em: 13 Fev. 2010."

Leia-se:

"BRASIL. Ministério da Saúde. Agência Nacional de Vigilância Sanitária. Portaria n 326, de 30 de julho de 1997. Dispõe sobre as Condições Higiênico-Sanitárias e de Boas Práticas de Fabricação para Estabelecimentos Produtores/ Industrializadores de Alimentos. Diário Oficial [da] República Federativa do Brasil. Brasília, DF, 3 maio 1997b. Disponível em: <http://www.anvisa.gov.br/alimentos/legis/especifica/regutec.htm>. Acesso em: 13 Fev. 2010."

Onde se lia:

"BRASIL. Ministério da Agricultura, Pecuária e Abastecimento. Instrução Normativa n 16, de 23 de agosto de 2005. Aprova o Regulamento Técnico de dentidade e qualidade de bebida láctea. Diário Oficial [da] República Federativa do Brasil. Brasília, DF, 24 ago. 2005. Disponível em: <http://extranet. agricultura.gov.br/sislegis-consulta/consultarLegislacao. do?operacao=visualizar\&id=12792>. Acesso em: 13 fev. 2010."

\section{Leia-se:}

"BRASIL. Ministério da Agricultura, Pecuária e Abastecimento. Instrução Normativa n 16, de 23 de agosto de 2005. Aprova o Regulamento Técnico de identidade e qualidade de bebida láctea. Diário Oficial [da] República Federativa do Brasil. Brasília, DF, 24 ago. 2005. Disponível em: <http://extranet. agricultura.gov.br/sislegis-consulta/consultarLegislacao. do?operacao=visualizar\&id=12792>. Acesso em: 13 fev. 2010."

Onde se lia:

"BRASIL. Ministério da Saúde. Agência Nacional de Vigilância Sanitária. Resolução - RDC n 18, de 27 de abril de 2010. Dipõe sobre Alimentos para Atletas. Diário Oficial [da] República Federativa do Brasil. Brasília, DF, 28 abr. 2010 a. Disponível em: <http://portal.anvisa.gov.br/wps/wcm/connect/52bee2804745886b91ffd53fbc4c6735/RDC_18_2010. pdf?MOD=AJPERES>. Acesso em: 12 nov. 2013."

Leia-se:

"BRASIL. Ministério da Saúde. Agência Nacional de Vigilância Sanitária. Resolução - RDC n 18, de 27 de abril de 2010. Dispõe sobre Alimentos para Atletas. Diário Oficial [da] República Federativa do Brasil. Brasília, DF, 28 abr. 2010 a. Disponível em: <http://portal.anvisa.gov.br/wps/wcm/connect/52bee2804745886b91ffd53fbc4c6735/RDC_18_2010. pdf?MOD=AJPERES > . Acesso em: 12 nov. 2013." 
No artigo Desenvolvimento, caracterização e análise sensorial de formulações alimentares com proteínas do soro de leite ou albumina para crianças publicado no periódico Brazilian Journal of Food Technology, vol. 18, n. 1: p. 31-41, na página 40 .

Onde se lia:

"SILVA, M. R.; SILVESTRE, M. P. C.; SILVA, V. D. M.; SOUZA, M. W. S.; LOPES UNIOR, C. O.; AFONSO, W. O.; LANA, F. C.; RODRIGUES, D. F. Production of ACE-inhibitory whey protein concentrate hydrolysates: use of pancreatin and papain. International Journal of Food Properties, New York, v. 17, n. 5, p. 1002-1012, 2014. http://dx.doi.org/10. 1080/10942912.2012.685821."

Leia-se:

"SILVA, M. R.; SILVESTRE, M. P. C.; SILVA, V. D. M.; SOUZA, M. W. S.; LOPES JUNIOR, C. O.; AFONSO, W. O.; LANA, F. C.; RODRIGUES, D. F. Production of ACE-inhibitory whey protein concentrate hydrolysates: use of pancreatin and papain. International Journal of Food Properties, New York, v. 17, n. 5, p. 1002-1012, 2014. http://dx.doi.org/10. 1080/10942912.2012.685821."

No artigo Desenvolvimento, caracterização e análise sensorial de formulações alimentares com proteínas do soro de leite ou albumina para crianças publicado no periódico Brazilian Journal of Food Technology, vol. 18, n. 1: p. 31-41, na página 41.

Onde se lia:

"SOUSA, G. T.; LIRA, F. S.; ROSA, J. C.; OLIVEIRA, E. P.; OYAMA, L. M.; SANTOS, R. V.; PIMENTEL, G. D. Dietary whey protein lessens several risk factors for metabolic diseases: a review. Lipids in Health and Disease, London, $\mathrm{V}$. 11, n. 67, p. 67, 2012. http://dx.doi.org/10.1186/1476-511X-11-67. PMid:22676328"

Leia-se:

"SOUSA, G. T.; LIRA, F. S.; ROSA, J. C.; OLIVEIRA, E. P.; OYAMA, L. M.; SANTOS, R. V.; PIMENTEL, G. D. Dietary whey protein lessens several risk factors for metabolic diseases: a review. Lipids in Health and Disease, London, $V$. 11, n. 67, p. 1-9, 2012. http://dx.doi.org/10.1186/1476-511X-11-67. PMid:22676328". 